\title{
COMPARISON BETWEEN MICROSCOPY AND RAPID DIAGNOSTIC TESTS IN DIAGNOSIS OF MALARIA AT A TERTIARY CARE MEDICAL INSTITUTION IN UTTARAKHAND (A 3-YEAR STUDY)
}

\author{
PRATIMA GUPTA ${ }^{1}$, PRIYANKA GUPTA ${ }^{1 *}$, SHALINEE RAO ${ }^{2}$, NEHA SINGH² ${ }^{2}$, DEEPJYOTI KALITA ${ }^{1}$
}

${ }^{1}$ Department of Microbiology, AIIMS, Rishikesh, Uttarakhand, India. ${ }^{2}$ Department of Pathology, AIIMS, Rishikesh, Rishikesh, Uttarakhand, India. Emial: dr.priyankagupta60@yahoo.com

Received: 21 August 2017, Revised and Accepted: 28 October 2017

\section{ABSTRACT}

Objectives: Malaria is one of the most prevalent parasitic diseases all over the world including India. Although the microscopic study of stained peripheral blood smear (PBS) is a gold standard of malaria diagnosis due to some subjective errors, rapid diagnostic tests (RDTs) can be a suitable alternative. This study was conducted to estimate the prevalence and demographic details of malaria cases along with a comparison between the two most common screening methods: PBS and RDTs.

Methods: Demographic profile, the prevalence of malaria in this region of Uttarakhand and evaluation of efficacy of RDT as a screening method was performed. Analysis of PBS microscopy for malaria parasites was performed and compared with immunochromatography based RDT over a duration of 3 years.

Results: Out of total 2982 clinically suspected patients of malaria, 132 were found to be positive by either of the two methods. Prevalence of malaria was $4.4 \%$ in our study. Plasmodium vivax was the predominant species isolated (95\%). Males outnumbered females with a ratio of 2.1:1. The most common age group affected was 30-49 years. Sensitivity and specificity of RDT was found to be $91.8 \%$ and $93.8 \%$, respectively. Positive predictive value and negative predictive value were found to be $97.8 \%$ and $98.9 \%$, respectively.

Conclusion: We conclude that Uttarakhand is a low prevalence area for Malaria and the RDT based on malaria antigen (whole blood) method is as specific and sensitive as the traditional PBS microscopy. Thus, it can be used as an alternative to PBS microscopy.

Keywords: Rapid diagnostic test, Sensitivity, Specificity, Microscopy, Malaria.

(c) 2018 The Authors. Published by Innovare Academic Sciences Pvt Ltd. This is an open access article under the CC BY license (http://creativecommons. org/licenses/by/4. 0/) DOI: http://dx.doi.org/10.22159/ajpcr.2018.v11i2.22141

\section{INTRODUCTION}

Malaria has been a continuous socioeconomic burden among almost all of the developing countries including India. Historically, malaria in our country was predominantly caused by Plasmodium vivax, accounting for $53 \%$ [1] of the estimated cases and also by far we have the greatest estimated $P$. vivax burden of any country. P. vivax accounts for approximately a third of all malaria cases in India while a study reported that states such as West Bengal, Gujarat, Madhya Pradesh, Orissa, Andhra Pradesh, and North-East being highly endemic for P. falciparum and they contribute to around $97 \%$ of the total P. falciparum affected cases in the country [2].

Microscopy and rapid diagnostic tests (RDTs) represent the two most commonly used methods for detection of malaria with the largest impact on malaria control today [3]. Although light microscopy is considered as gold standard, it has its own characteristic strengths and limitations. It is prone to inherent errors due to sample handling, staining, and individual reader techniques [4-6]. According to Kilian et al. and Bell et al., in case of low parasitemia $(<50 / \mathrm{ml})$ microscopy is less reliable $[7,8]$. In contrast, RDT kits are equally sensitive, specific, and stable under operational conditions and does not require extensive training or any equipment to perform or to interpret the results, and commercially available with all necessary reagents [9-11]. Moody and Leke et al. also reported that results of RDTs are rapidly available and less liable of being falsely negative due to parasite sequestration [12,13]. Antimalarial drug resistance and economic loss due to increased morbidity and mortality, there is an urgent requirement of improvement of parasite-based diagnostic methods with good quality and their availability to people living in endemic areas.

\section{METHODS}

This retrospective study was conducted in a tertiary care medical institution at Rishikesh, Uttarakhand. Blood samples were collected in Ethylenediaminetetraacetic acid vials from 2982 patients who were clinically suspected for malaria. Thick and thin smear microscopy and RDTs were done on these blood samples collected over 3 years. The patient's name, age, sex, details of fever, and other symptoms and clinical examination findings were recorded.

Thick and thin films were made within 10 min of collection and stained by Leishman's stain. RDT based on Lactate dehydrogenase/Histidinerich Protein-2 antigens was carried out on aliquots of whole blood.

As per diagnostic modality requested by clinicians, samples were divided into three groups.

1. Group 1 represents the samples which were only sent for peripheral blood smear (PBS) microscopy.

2. Group 2 represents the samples which were only sent for RDT.

3. Group 3 represents the samples which were sent for both PBS microscopy and RDTs.

Statistical analysis

All data were analyzed using Statistical Package for the Social Sciences (SPSS) version IBM SPSS-23. Data are represented in the form of frequency and percentage.

\section{RESULTS}

Out of 2982 samples screened for malaria, 132 samples tested positive. Among 132 positive samples, 41 were detected in Group 1, 42 were 
Table 1: Demographic details of the malaria patients $(n=132)$

\begin{tabular}{|c|c|c|}
\hline Gender & Male $(n=89)$ mean \pm SD & Female $(n=43)$ mean \pm SD \\
\hline \multicolumn{3}{|l|}{ Age (years) } \\
\hline $0-18$ & $12.21 \pm 2.92$ & $13.75 \pm 3.09$ \\
\hline $19-29$ & $23.09 \pm 2.55$ & $24.15 \pm 2.17$ \\
\hline $30-49$ & $38.02 \pm 5.67$ & $35.85 \pm 4.54$ \\
\hline$\geq 50$ & $58.11 \pm 5.9$ & $54.83 \pm 2.96$ \\
\hline Geographic location & Haridwar, Pauri Garhwal, Bijnor & \\
\hline Seasonal distribution & July-September & \\
\hline
\end{tabular}

SD: Standard deviation, $P$. falciparum: Plasmodium falciparum, $P$. vivax: Plasmodium vivax

Table 2: Sensitivity, specificity, PPV and NPV of RDT

\begin{tabular}{|c|c|c|}
\hline Stastical analysis & Total screened $(n=2982)$ & Malaria positive $(n=132)$ \\
\hline Group 1 & 1521 & 41 \\
\hline Group 2 & 1045 & 42 \\
\hline Group 3 & 416 & 49 \\
\hline Sensitivity & $91.8 \%$ & \\
\hline Specificity & $93.8 \%$ & \\
\hline PPV & $97.8 \%$ & \\
\hline NPV & $98.9 \%$ & \\
\hline
\end{tabular}

PPV: Positive predictive value, NPV: Negative predictive value, RDT: Rapid diagnostic test

detected in Group 2, and 49 were detected in Group 3. Prevalence of malaria was found to be $4.4 \%$. Predominant species detected in our study was P. vivax ( $n=125 / 132,95 \%)$, maximum prevalence was found to be in the month of July-September. Males (67.4\%) outnumbered females (33.3\%) in our study with ratio being 2.1:1 (Table 1). The most common age group affected was between 30 and 49 years of age with $12.1 \%$ in children in age group of $0-18$ years.

Out of 49 malaria positive samples using both methods, four samples were found to be malaria positive by PBS microscopy only and 45 were found malaria positive by both of the methods and one by RDT alone. Sensitivity and specificity of RDT was found to be $91.8 \%$ and $93.8 \%$ by taking PBS microscopy as gold standard (Table 2).

\section{DISCUSSION}

Malaria is a major vector-borne disease in India. Extensive geographical areas, climatic diversity and variable malaria epidemiology in India is associated with high parasite genetic diversity and rapidly evolving drug resistance. Thus, epidemiological studies along with their screening methods and modern biological studies could help to find enduring solutions in future. Malaria is a major global public health concern. Annually, there occurs approximately 300 million of clinical cases and over 1 million of deaths worldwide due to malaria [14]. Prevalence rate of malaria at our tertiary care was found to be $4.4 \%$. Jivabhai et al., from Gujarat and Karlekar et al., from Gadchiroli (Maharashtra) also reported a similar prevalence of $2.10 \%$ and $4.28 \%$, respectively [15-18]. However, Kumar et al. from Udaipur, Rajasthan (14.4\%), Singh et al. from Mumbai (16.58\%), Sahu et al. from Orissa (16.5\%) Pandey and Manwani from Bilaspur (24.74\%), Baruah et al. (30.2\%) from Nagaland, Das et al. from Assam (49.1\%) [19-22], and Satyanarayana et al. from tribal belt of Andhra Pradesh (69.1\%) reported a much higher prevalence. Some of these studies are hospital based, and others have conducted field survey's [23]. Hence, variations in prevalence might be due to different study settings, differing ecological conditions, along with socioeconomic conditions of patients and local public health practices which determine mosquito breeding and spread. Like these studies, most of the malaria cases were detected in the mosquito breeding rainy season of July-September.

In the current study, $P$. vivax was the predominant species identified in $95 \%$ cases followed by $P$. falciparum (5\%). Our findings were similar to Kumar et al. from Rajasthan and Jivabhai et al. from Gujarat, who have reported $P$. vivax as the predominant species in $69 \%$ and $61.41 \%$ cases, respectively [15-17]. However, P. falciparum as the predominant species have been reported from studies from Nagaland (76.5\%), Assam (97.1\%), and Orissa (89.1\%) $[19,21,22]$. The difference in prevalence in different areas is due to the regional endemicity of a particular Plasmodium species.

Malaria is usually diagnosed using clinical criteria, with microscopy as the current gold standard even though it is not appropriate in many health-care settings. In recent years, RDTs have been considered as an ideal alternative method for diagnosing malaria $[24,25]$. Today's multimillion dollar investment in antimalarial drug and vaccine development should be accompanied by a parallel commitment to improve diagnostic tools and their availability to those living in endemic malaria areas. Wongsrichanalai et al. Suggested that RDT is a valuable complement to microscopy because it helps in reducing the over diagnosis based on clinical symptoms only and thus widens the coverage of parasite-based diagnosis to the periphery [6]. Similarly, Jessica et al. recommended the use of RDT in conjunction with microscopy $[25,26]$. These studies are in concordance with our study where sensitivity and specificity of RDTs was found to be $91.8 \%$ and $93.8 \%$, respectively.

\section{CONCLUSION}

Malaria should always be considered as a medical emergency, and an early diagnosis should be made so that we could prevent its further spread in community. Although RDTs are best alternative to microscopy till date, their high cost and low specificity have been a matter of concern. However, in contrast, we found high sensitivity as well as high specificity of RDT as compared with microscopy in our study.

Thus, we conclude that RDTs can be used for confirming clinical diagnosis and for starting early and prompt treatment of malaria which would surely decrease the morbidity and mortality in the hospital as well as in field settings especially in a low prevalence area like Uttarakhand.

\section{REFERENCES}

1. Anvikar AR, Shah N, Dhariwal AC. Epidemiology of Plasmodium vivax malaria in India. Am J Trop Med Hyg 2016;95:108-20.

2. Sharma RB, Chetia D. Docking studies on quinine ana LOGS for plasmapepsin- II Of malaria parasite using bioinformatics tools 2013. Int J Pharm Pharm Sci 2013;5:681-5.

3. Hay SI, Guerra CA, Gething PW, Patil AP, Tatem AJ, Noor AM, et al. A world malaria map: Plasmodium falciparum endemicity in 2007. 
PLoS Med 2009;6:e1000048

4. World Health Organization. The Use of Malaria Rapid Diagnostic Tests. $2^{\text {nd }}$ ed. Geneva: WHO; 2006

5. Bell D, Wongsrichanalai C, Barnwell JW. Ensuring quality and access for malaria diagnosis: How can it be achieved? Nat Rev Microbiol 2006;4:682-95.

6. Wongsrichanalai C, Barcus MJ, Muth S, Sutamihardja A, Wernsdorfer WH. A review of malaria diagnostic tools: Microscopy and rapid diagnostic test (RDT). Am J Trop Med Hyg 2007;77:119-27.

7. Bel DR, Wilson DW, Martin LB. False-positive results of a Plasmodium falciparum histidine-rich protein 2-detecting malaria rapid diagnostic test due to high sensitivity in a community with fluctuating low parasite density. Am J Trop Med Hyg 2005;73:199-203.

8. Kilian AH, Metzger WG, Mutschelknauss EJ, Kabagambe G, Langi P, Korte R, et al. Reliability of malaria microscopy in epidemiological studies: Results of quality control. Trop Med Int Health 2000;5:3-8

9. Murray CK, Bell D, Gasser RA, Wongsrichanalai C. Rapid diagnostic testing for malaria. Trop Med Int Health 2003;8:876-83.

10. Reyburn H, Mbakilwa H, Mwangi R, Mwerinde O, Olomi R, Drakeley $\mathrm{C}$, et al. Rapid diagnostic tests compared with malaria microscopy for guiding outpatient treatment of febrile illness in Tanzania: Randomised trial. BMJ 2007;334:403.

11. Mills CD, Burgess DC, Taylor HJ, Kain KC. Evaluation of a rapid and inexpensive dipstick assay for the diagnosis of Plasmodium falciparum malaria. Bull World Health Organ 1999;77:553-9.

12. Moody A. Rapid diagnostic test for malaria parasites. Clin Microbiol Rev 2002;15:66-78.

13. Leke RF, Djokam RR, Mbu R, Leke RJ, Fogako J, Megnekou R, et al. Detection of the Plasmodium falciparum antigen histidine-rich protein 2 in blood of pregnant women: Implications for diagnosing placental malaria. J Clin Microbiol 1999;37:2992-6.

14. Widyawaruyanti A, Puspita AD, Fatria N, Tumewu L, Tantular SI, Hafid AF. In vitro antimalarial activity screening of several Indonesian plants using HRP2 assay. J Pharm Pharm Sci 2014;6:125-8.

15. Jivabhai HT, Kanubhai VB, Hariharbhai AA, Animeshbhai DG, Kanubhai VV. Retrospective study of malaria cases attending at tertiary care level hospital in Rajkot city, Gujarat. Int J Curr Res 2014;6:6273-6.

16. Karlekar SR, Deshpande MM, Andrew RJ. Prevalence of asymptomatic Plasmodium vivax and Plasmodium falciparum infections in tribal population of a village in Gadchiroli district of Maharashtra state, India. Biol Forum Int J 2000;4:42-4.

17. Kumar S, Khan N. Prevalence and detection of malaria at a tertiary care hospital in southern Rajasthan, India. Int J Curr Microbiol App Sci 2016;5:663-8.

18. Singh G, Urhekar AD, Maheshwari U, Sharma S, Raksha. Prevalence of Malaria in a Tertiary hospital in Navi Mumbai, India. J Bacteriol Parasitol 2000; 6(2):221-4.

19. Sahu SS, Gunasekaran K, Vanamail P, Jambulingam P. Persistent foci of falciparum malaria among tribes over two decades in Koraput district of Odisha state, India. Malar J 2013;12:72.

20. Pandey S, Manwani VK. A retrospective study of malaria prevalence at Bilaspur District (Chhattisgarh), India. Int J Sci Res 2014;3:2277-8179.

21. Baruah I, Das NG, Das SC. Studies on anopheline fauna and malaria incidence in Dhansiripar PHC of Dimapur, Nagaland. J Vector Borne Dis 2004:41:67-71

22. Das NG, Baruah I, Kamal S, Sarkar PK, Das SC, Santhanam K. An epidemiological and entomological investigation on malaria outbreak at Tamalpur PHC, Assam. Indian J Malariol 1997:34:164-70.

23. Satyanarayana P, Meka FB, Dulala RK, Raoc KR. An epidemiological study on clinical profile of malaria in Rampachodavaram and Maredumilli the tribal belt of east Godavari, Andhra Pradesh, India. Asian Pac J Trop Dis 2014;4:S221-5.

24. Prakash A, Mohapatra PK, Bhattacharyya DR, Doloi P, Mahanta J. Changing malaria endemicity-a village based study in Sonitpur, Assam. J Commun Dis 1997;29:175-8

25. Jessica M, Gillet P, Cnops L, Bottieau E, Esbroeck MV, Bruggeman C, et al. Evaluation of the rapid diagnostic test SDFK40 (Pf-p LDH/pan-p $\mathrm{LDH}$ ) for the diagnosis of malaria in a non-endemic setting. Malar J 2001:10:7

26. Murray CK, Gasser RA Jr., Magill AJ, Miller RS. Update on rapid diagnostic testing for malaria. Clin Microbiol Rev 2008;21:97-110. 